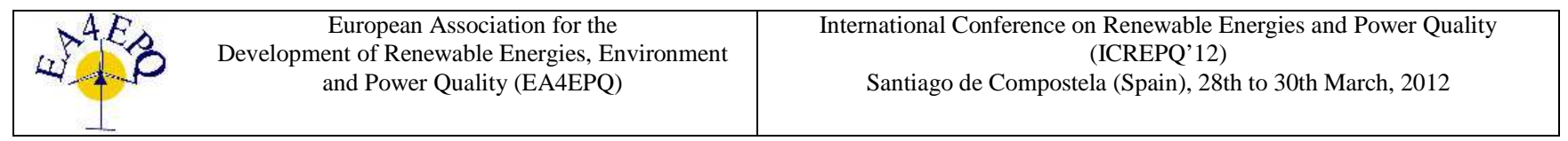

\title{
Output DC Voltage Control Strategy for Switched Reluctance Generator
}

\author{
G.P.Viajante ${ }^{1}$, D.A.Andrade ${ }^{2}$, A. W. F. V. Silveira ${ }^{2}$, M.A.A.Freitas ${ }^{1}$,L.C.Gomes ${ }^{2}$, V. R. Bernardeli ${ }^{2}$, \\ L.G.Cabral ${ }^{2}$ and M. B. Rêgo ${ }^{2}$ \\ ${ }^{1}$ Federal Institute of Education, Science and Technology of Goiás \\ Campus of Itumbiara - Goiás, (Brazil) \\ Phone/Fax number: 5564 343152005, e-mail: A. ghunterp@gmail.com \\ ${ }^{2}$ Federal University of Uberlandia \\ Campus Santa Mônica
}

Phone/Fax number: 5534 3239-4411, e-mail: B. darizon@ufu.br

\begin{abstract}
This paper presents a proposed generated voltage control for a Switched Reluctance Generator (SRG). The strategy developed uses a PI controller to vary the magnetization angle of the machine phases, acting in the top switches opening angle $\left(\theta_{\text {off }}\right)$ of the converter. The strategy is used together with the freewheel intermediate step, between the steps of magnetization and demagnetization of the phases. The main vantage is decrease the input power of the excitation source and to get the better use of mecanic energy to increase the phase current of the generator, maximizing the electric energy production. Is used the classic half-bridge converter without the need to alteration in your project, changing only the switching strategy. A nonlinear model of the SRG and the control strategy were implemented in MatLab/Simulink. The experimental platform was developed to validate the proposal presented.
\end{abstract}

\section{Key word}

Switched Reluctance Generator, HB Converter and Voltage Control

\section{Introduction}

The Switched Reluctance Generator (SRG) has been subject in research for applications that require variable speed, which its constructive characteristics make it competitive in relation to others types of machine [1]. There are several applications where its use has been explored: electricity generation in aircrafts [2], automobiles [3-4] and wind energy [5]. In the case of aeronautics and automotive applications the operation in variable speeds is requirement of compability with the primary mechanic machine and that usually works in high speeds. These applications, the demand for generated power tends to oscillate sharply with the input and output of the loads that proportionally represent high transients for the electrification system. Since the applications in wind energy, research has been realized for the adaptation of the SRG in the range of low and medium rotation in speed variable. The aim of the control in this application is to optimize the captured energy to produce maximum output power [6-7].

Several techniques of generated voltage control by the SRG has been proposals in last years in function of the voltage available in its terminals to suffer influence of variation speeds and the load. About of these techniques the authors in [8] compare three strategies to control the applied voltage to the load and claim that the PWM control with fixed shooting angle and the technique of the excitation voltage control has similar performance and have lower efficiency comparing with the technique of variation of the opening angle $\left(\theta_{\text {off }}\right)$. In [9] the generated voltage is regulated keeping $\theta_{\text {off }}$ fixed and varying $\theta_{\text {on }}$ (closing angle of the switches) through an algorism based in fuzzy logic, showing that the efficiency increase with the increase on the rotor speed.

Before this information's, this paper presents a proposal of a strategy to control the generated voltage based on the variation of magnetization angle $\left(\theta_{\text {off }}\right)$ only on the top switches of the HB converter. A step of intermediate freewheel is added in the strategy of control to allow a better use of the mechanic energy source. A detailed description is commented to substantiate its importance on the control strategy proposed. The strategy was simulated and validated through experimental results.

\section{Nonlinear Model for Dynamic Analysis of the SRG}

The mathematic model for the dynamic analysis of the SRG is described using one phase of the machine like reference so that is described as

$$
v=R i+\frac{\partial \lambda(i, \theta)}{d t}
$$

With a constant speed, the voltage equation of the phase is

$$
v=R i+l \frac{d i}{d t}+e
$$

where $v$ is the applied voltage, $i$ is the phase current, $R$ is the phase resistance, $e=\omega_{r} \partial \lambda(i, \theta) / \partial \theta$ is the back emf, $l=\partial \lambda(i, \theta) / \partial i$ is the incremental phase inductance, $\theta$ is the rotor position.

The saturation effects are considered on the model through the representation of the variation on phase inductance in function of the current and the rotor position using an approximation of the Fourier Series. 
The inductance function for this prototype tested in this work was determinated as

$$
\begin{aligned}
& L(i, \theta)=\frac{1}{G} \sum_{j=1}^{m}\left(l_{(j+1)}\left(i, \alpha_{j}\right)+l_{j}\left(i, \alpha_{j}\right)\right)\left(\alpha_{(j+1)}-\alpha_{j}\right)+ \\
& \sum_{n=1}^{\infty}\left(\sum_{j=1}^{m}\left(l_{(j+1)}(i) A_{(j, n)}-l_{j}(i) B_{(j, n))}\right)\right) \cos \left(n P_{r} \theta\right)
\end{aligned}
$$

where:

$$
\begin{gathered}
A_{(j, n)}=\frac{2}{n \pi}\left(\sin \left(n P_{r} \alpha_{\left(j_{n}+1\right)}\right)+\frac{\cos \left(n P_{r} \alpha_{\left(j_{n}+1\right)}\right)-\cos \left(n P_{r} \alpha_{j}\right)}{n N_{r}\left(\alpha_{\left(j_{n}+1\right)}-\alpha_{j}\right)}\right) \\
B_{(j, n)}=\frac{2}{n \pi}\left(\sin \left(n P_{r} \alpha_{j}\right)+\frac{\cos \left(n P_{r} \alpha_{(j+1)}\right)-\cos \left(n P_{r} \alpha_{j}\right)}{n N_{r}\left(\alpha_{\left(j_{n}+1\right)}-\alpha_{j}\right)}\right)
\end{gathered}
$$

$m$ is the number of line segments, $n$ is the harmonic order, $P_{r}$ is the number of rotor poles, $G=2 \pi / P_{r}$ is the polar step of the rotor, $\theta$ is the rotor position, $l_{j}$ is the inductance for j'ésimo segment, $\alpha_{j}$ is the position associated to this inductance, according Fig. 1 and Fig. 2.

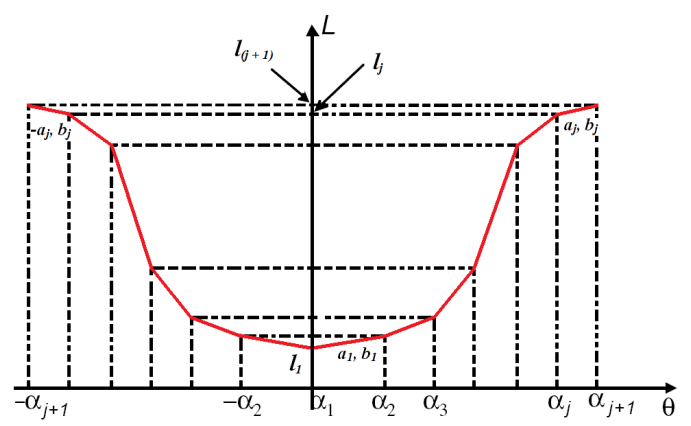

Fig.1. Approximate representation of the inductance profile using "j" straight line segments

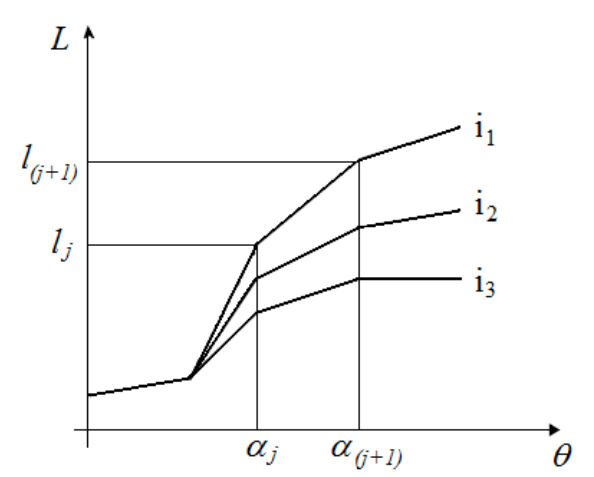

Fig.2. - Line segments of inductance versus rotor position

More details in relation to the inductance representation using Fourier can be found in [11].

The electromagnetic torque produced for a phase is expressed as

$$
T(i, \theta)=\frac{\partial W_{c}(i, \theta)}{\partial \theta}
$$

where $W_{c}$ is the co-energy which is given by

$$
W_{c}=\int_{0}^{i} \lambda(\xi, \theta) d \xi
$$

From the equations presented, the mathematical model that describes the dynamic of the SRG can be presented in states matrix form by means of

$$
[v]=[X][i]+[Y][\dot{\bullet}]
$$

Where $\mathrm{X}$ and $\mathrm{Y}$ are matrices that depend the constructive parameters of machine. The solution of the system thus allows a complete analysis of SRG [8] [10].

\section{Switching Strategy}

In this work is proposed a switching strategy for the HB converter (Half-Bridge), which is connected to the SRG phases so that make possible an increment on the generated electric energy when compared to the classic switching strategy. The HB converter is presented on Fig. 3 and it was assumed that $\theta_{\text {off }}=\theta_{\text {offl }}$ during a variation cycle of inductance in one phase as shown in Fig 4.

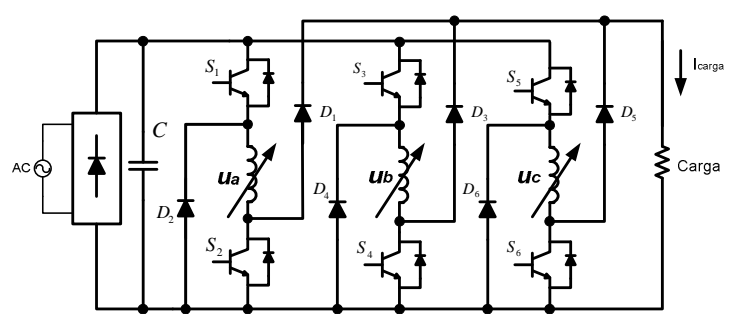

Fig.3. Schematic diagram of the HB Converter

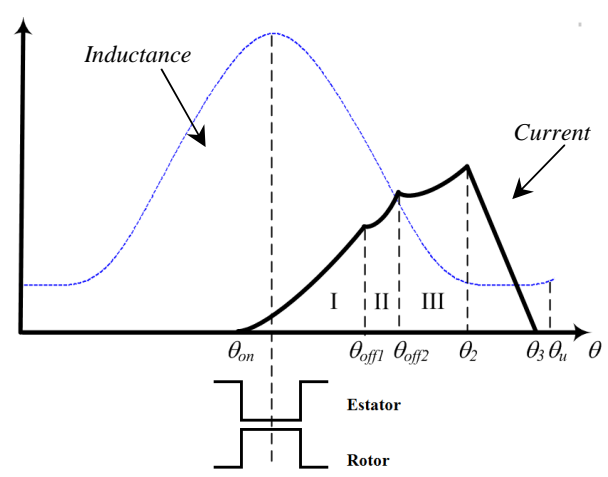

Fig. 4- Variation of the inductance and current of one phase as a function of rotor position.

The classic switching function of the HB converter to operate a SRG is usually given by [12].

$S\left(S_{1}, S_{2}\right)= \begin{cases}1 & S_{1}, S_{2}: \text { on }\left(\theta_{o n}<\theta \leq \theta_{\text {off } 1}\right) \\ -1 & S_{1}, S_{2}: \text { off }\left(0<\theta \leq \theta_{\text {on }}, \theta_{\text {off } 1}<\theta \leq \theta_{3}\right)\end{cases}$

The voltage function of the phase can be described as

$$
u(S)= \begin{cases}u_{a} & S=1 \\ -u_{a} & S=-1\end{cases}
$$

A intermediate freewheel step was added to compare with the classic model. The switching function for one phase is given by 


$$
S\left(S_{1}, S_{2}\right)= \begin{cases}1 & S_{1}, S_{2}: \text { on }\left(\theta_{o n}<\theta \leq \theta_{\text {off } 1}\right) \\ 0 & S_{1}: \text { off }, S_{2}: \text { on }\left(\theta_{o f f 1}<\theta \leq \theta_{\text {off } 2}\right) \\ -1 & S_{1}, S_{2}: \text { off }\left(0<\theta \leq \theta_{\text {on }}, \theta_{\text {off } 2}<\theta \leq \theta_{3}\right)\end{cases}
$$

The voltage function on the phase can be described as

$$
u(S)= \begin{cases}u_{a} & S=1 \\ 0 & S=0 \\ -u_{a} & S=-1\end{cases}
$$

As can be seen in (10), the strategy presented provides three different levels of voltage for the winding stator phase: $1,0 \mathrm{e}-1$ which is equivalent $u_{a}, 0 \mathrm{e}-u_{a}$. In this case the operating procedure of the SRG becomes realized in three steps: excitation region, intermediate freewheel region and generation freewheel region. These steps (I, II e III) are in highlighted on Fig. 4 and will be described bellow for one phase cycle.

\section{Step I - Excitation $\left(\theta_{o n}<\theta \leq \theta_{\text {off } 1}\right)$}

Initially the magnetization current is established through the closing of the switches $S_{1}$ and $S_{2}$ of the HB converter, according to the Fig. 5(a). This current is responsible for the magnetization flux in the core, which produces a restorer torque that results in a back emf to the excitation voltage. In this step, both voltage sources contribute to the increment of current. The switches $S_{1}$ and $\mathrm{S}_{2}$ are closed just before the alignment position for better use of the magnet flux when the machine is operating in higher speeds.

\section{Step II- Intermediate Freewheel $\left(\theta_{o f f 1}<\theta \leq \theta_{\text {off } 2}\right)$}

The intermediate freewheel step originates with the opening switch $S_{1}$. In this step the energy flux circulates through the diode $\mathrm{D}_{2}$ and the switch $\mathrm{S}_{2}$ according to Fig. 5(b). The current on the phase remains incremented through the back emf. Therefore, no current is requested from the excitation source and the increased energy to the inductor is proceeding only from the electromechanical conversion.

\section{Step III - Freewheel on Generation $\left(\theta_{\text {off } 2}<\theta \leq \theta_{3}\right)$}

This step happens with the opening of the switch $S_{2}$. The winding of the winding stator changes its direction, starting the energy transfer process to the load, according to Fig. 5(c). In this region, due the back emf, the current on the phase continues to increase and reaches its peak values $\theta_{2}$.

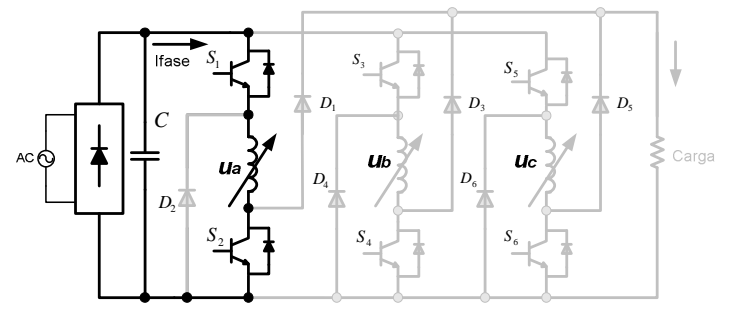

(a)

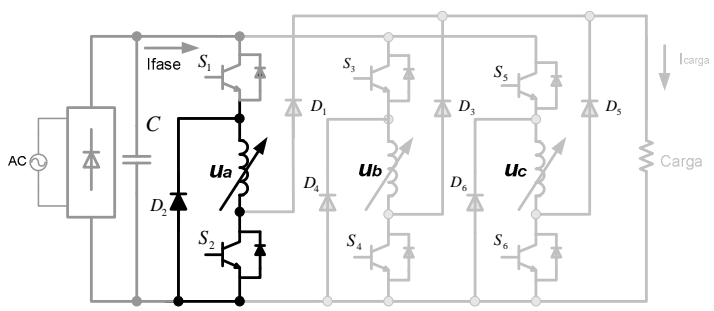

(b)

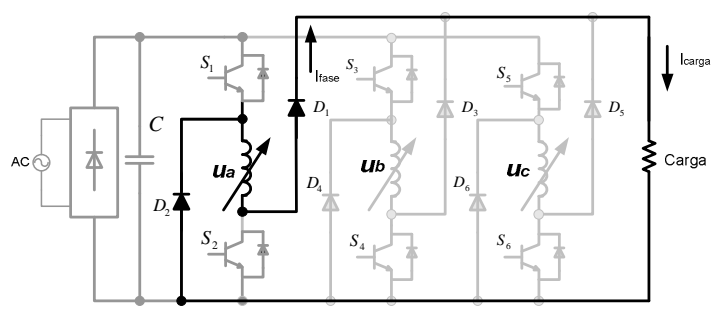

(c)

Fig. 5. Region of excitation (a) Region free-wheeling intermediate (b) Region freewheeling generation (c).

\section{Simulation Results}

\section{A. Open loop operation of SRG}

To illustrated the practicality of switching strategy with intermediate freewheel, are realized simulations of the SRG with HB converter operating with classic switching and with the proposed strategy for different values of $\theta_{\text {off }}$. In both situations the SRG operated with speed of $1500 \mathrm{rpm}, \theta_{o n}$ fixed in $-3^{\circ}$ in relation to the alignment position, load of $25 \Omega$ and excitation voltage fixed in $80 \mathrm{~V}$. Here considered as electricity production the relation between the electric energy dissipated in the load by the electric energy used in the magnetization. The Fig. 6 illustrates the electricity production in function of $\theta_{\text {off }}$ for the two situations. Can be observed a strong influence of the angle variation $\theta_{\text {off }}$ on the electricity production and that during all the scanning range $\theta_{\text {off }}$ the production is higher when use the strategy of intermediate freewheel.

In sequence of simulation was chosen and fixed the value of $\theta_{\text {off }}$ in $22^{\circ}$ that corresponds in a value where the electricity production is higher than $100 \%$ for both strategies. The SRG operated in same conditions described before. The figures 7 and 8 shows the current phase waveforms in the phase A of the stator, even as the pulses of switching of the bottom and top switches of the HB converter.

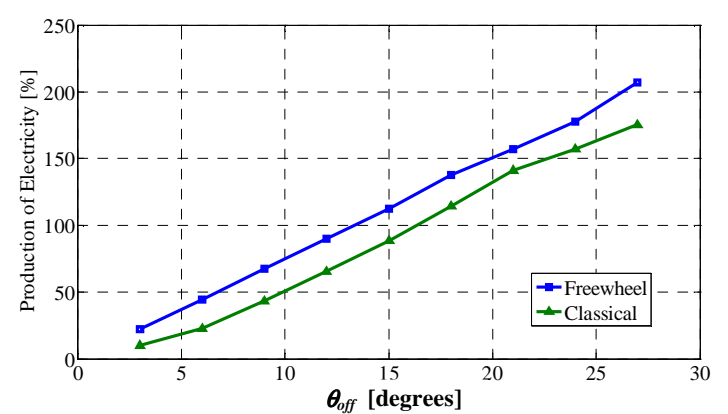

Fig. 6. Production of electricity due to $\theta_{\text {off }}$ to the strategies classical and the intermediate freewheel 


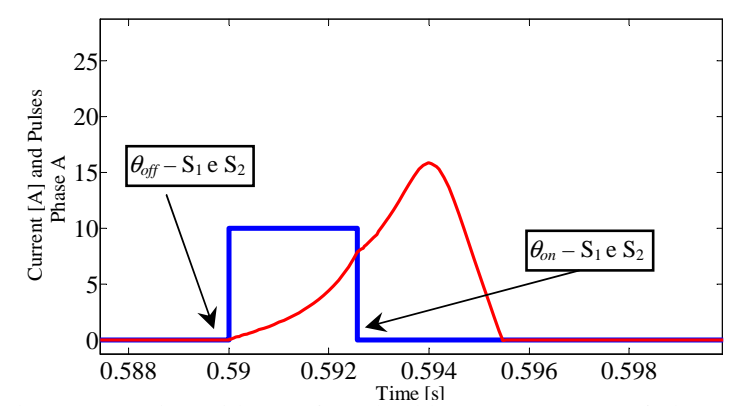

Fig. 7- Operating without a freewheel between. Current of Phase A and pulses $\mathrm{S} 1$ and $\mathrm{S} 2$

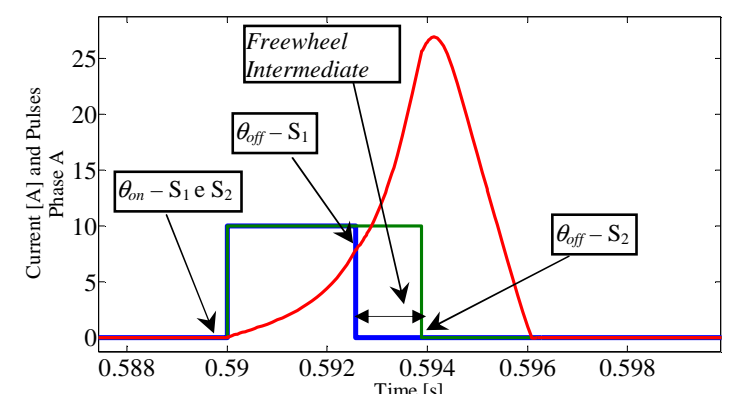

Fig. 8 - Intermediate operation with freewheel. Current of Phase A and pulses $\mathrm{S} 1$ and $\mathrm{S} 2$

Notes that the current in the excitation step is the same in the two situations however the maximum magnitude of the phase current in the strategy presented is larger than in the classic mode. This highlights a better use of mechanicelectric conversion of the SRG, once that this increase in the current is due to the action of the back emf in the intermediate freewheel step.

\section{B. Closed loop operation of SRG}

For operation in closed loop with generated voltage control was developed a strategy that consist in the variation of width of the magnetization period of phases, keeping $\theta_{o n}$ fixed in $-3^{\circ}$ and choosing the value of $\theta_{\text {off }}$ through a PI controller. The differential of the strategy is that the action of the controller is done only on the top switch of the converter. The bottom switch is keeping in conduction since that the $30^{\circ}$ are completed to allow the intermediate freewheel step occurs between the steps of magnetization and demagnetization of the phases. Then the bottom switch off the converter is open doing that the energy stored in the coil is delivered to the load. It is noteworthy that this variation occurs in the same way for the other phases of the machine, whereas the PI controller changes the value of $\theta_{\text {off }}$ for all the (three) phases. The block diagram of simulation is presented in Fig. 9.

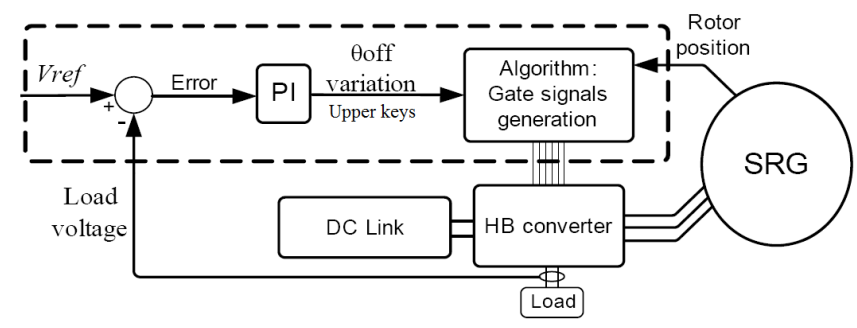

Fig. 9- Block diagram of the simulation
The simulation tests were realized with the following criteria: the reluctance generator operated in closed loop using the strategy described above, excitation voltage fixed in $80 \mathrm{~V}$, reference voltage of the controller in $110 \mathrm{~V}$ and rotor speed in $1500 \mathrm{rpm}$. The machine was simulated during 6 seconds. Was submitted a load transient where the resistance of the same was reduced from $25 \Omega$ to 11 $\Omega$ with 1,5 s of simulation and when the time reached $4,5 \mathrm{~s}$, the load resistance returns for its initial value.

The Fig. 10 shows the behavior of the generator voltage applied to the load during the load transient. Notice that the reference value $(110 \mathrm{~V})$ was properly maintained. This test showed that the control was able to keep with precision the generated voltage around the reference value even during the load transients. For the same situation Fig 10 shows the current in one of the machine phases.
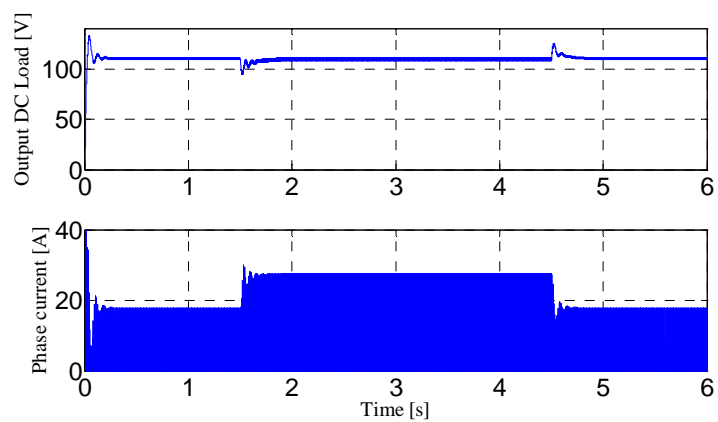

Fig. 10- Behaviour of the generated voltage (top) and phase current (below) during transient load

\section{Experimental Platform}

To validate the proposed and simulated strategy was developed with success an experimental platform. The Fig. 11 presents the block diagram of the assembly held. The platform consists of a SRG of $6 \mathrm{HP} 6 / 4$ coupled in a three-phase motor operated with a frequency converter. A not controlled rectifier bridge with a capacitor of $20 \mathrm{mF}$ was used to supply the input power of the grid AC. The variable voltage source was used to regulate the excitation voltage. The HB converter was mounted with IGBT's modules of 1200V/50A. A PI controller was designed with analogic circuits.

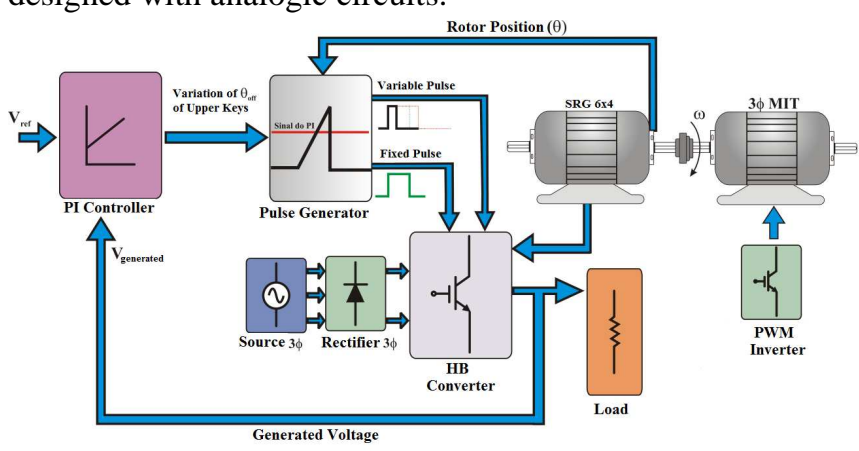

Fig. 11- Block diagram of the experimental platform

Three photoelectric transducers properly installed on the SRG $\left(\theta_{o n}\right.$ fixed in $-3^{\circ}$ in relation to the alignment position) provide signals in square waves with intervals 
of $30^{\circ}$ that represents the information about the rotor position. These signals enter in the pulse generator circuit that transforms in ramp corresponding to the same interval for each phase. So, the variation of the width of the trigger pulses of top switches occurs with the comparing between the output signals of the PI controller with the three ramps generated. The bottom switches has conduction intervals fixed in $30^{\circ}$ and do not suffer with the controller performance. The Fig. 12 illustrates the strategy used.

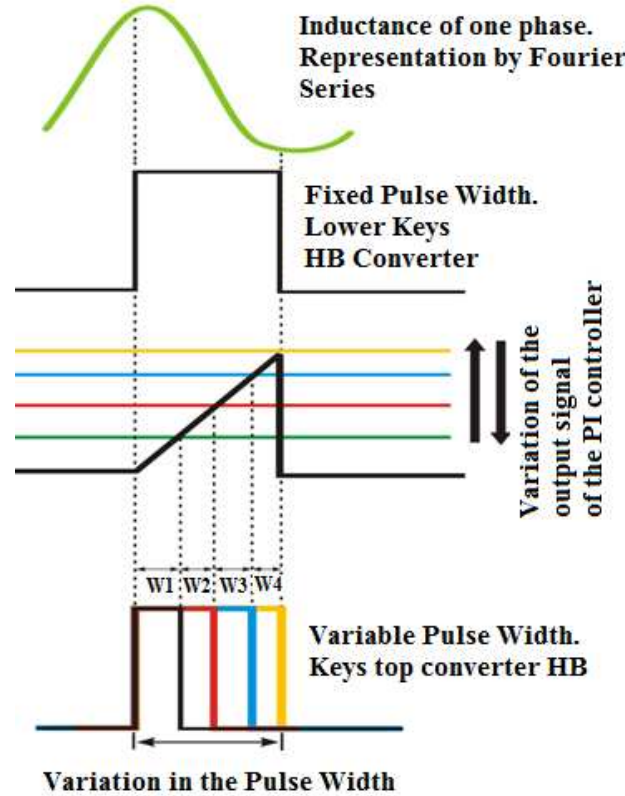

Fig. 12 - Experimental strategy to change the angle of magnetization of the top key

In open loop in place of the output signal of PI controller is used a voltage signal in direct current (dc) whose amplitude can be changed until the signal peak value in ramp. In this way is possible to adjust the magnetization angle adjusting the level of the voltage signal dc that is compared with the generated ramp in the pulses generator circuit. A photo of the experimental platform is showed in Fig. 13.

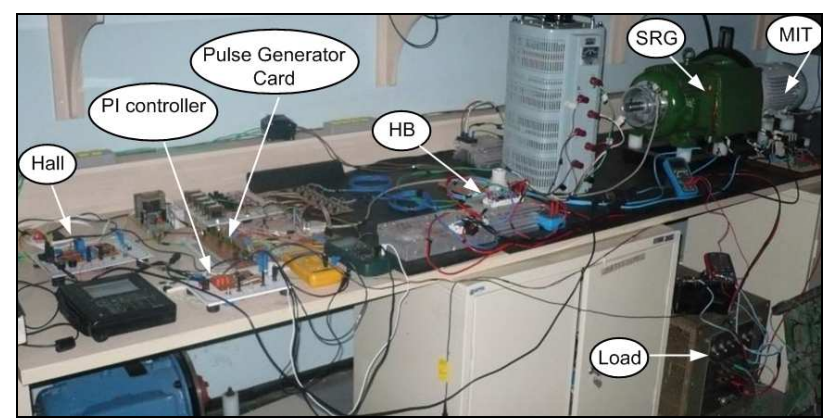

Fig. 13- Experimental platform

\section{Experimental Results}

Initially tests were realized with the SRG operating in open loop without intermediate freewheel strategy and after was added the step for the comparison.
Thus, without the intermediate freewheel step, was adjusted the opening angle of the switches $\left(\theta_{\text {off }}\right)$ in $22^{\circ}$. The Fig. 14 shows the waveforms of the applied pulses in the switches $S_{1}$ e $S_{2}$, current and voltage of phase A and the voltage in resistive load. In this situation the SRG operates with excitation voltage in $80 \mathrm{~V}$, speed of $1500 \mathrm{rpm}$ and load of $25 \Omega$. In these operation conditions the voltage generated was around of $100 \mathrm{~V}$ while that the current peak in the phase reached the value of $12 \mathrm{~A}$.

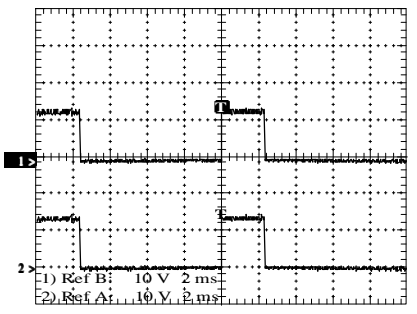

(a)

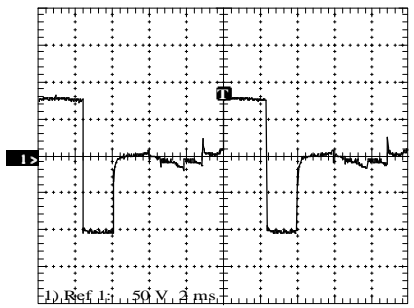

(c)

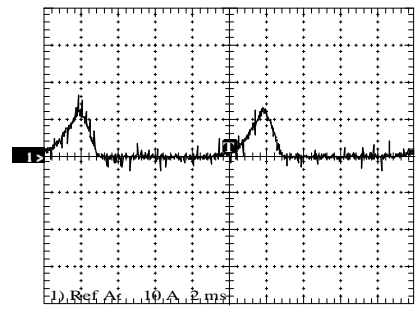

(b)

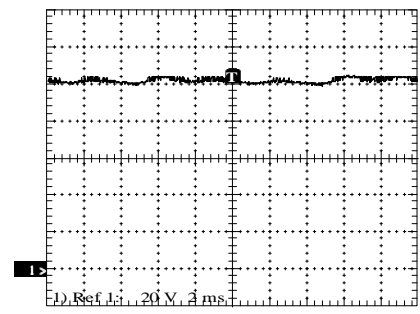

(d)
Fig. 14- Operation without the freewheel intermediate strategy. Pulses S1 and S2 (a) - Current in Phase A (b) - Voltage in phase A (c) Voltage at Load (d)

In sequence, the tests were realized adding the intermediate freewheel step for the same conditions described before. Can be observed in Fig. 15(d) that the generated voltage reached the approximately value of $132 \mathrm{~V}$ and that the current peak of the phase 30A, according Fig. 15(b). In other words, with the intermediate freewheel step was a increase of $32 \%$ in the voltage generated.

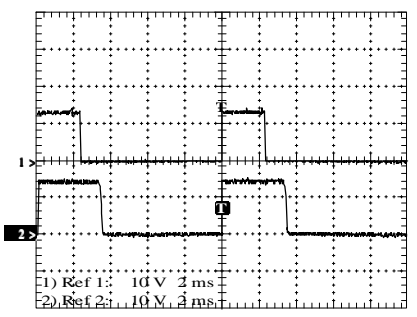

(a)

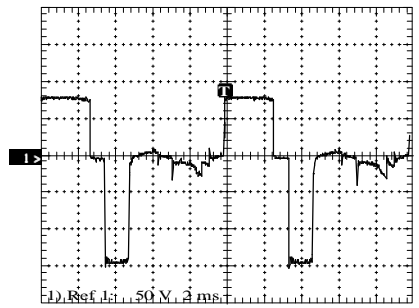

(c) (b)

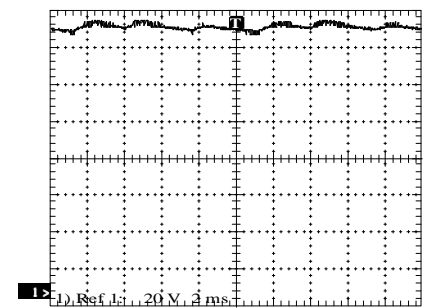

(d)

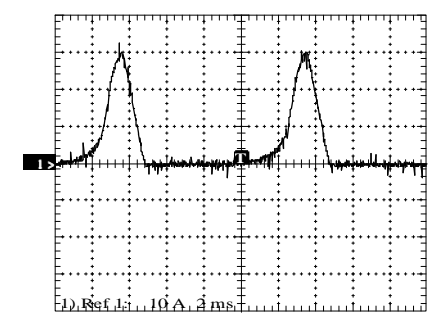

Fig. 15- Operation with the strategy of intermediate freewheel. Pulses S1 and S2 (a) - Current in Phase A (b) - voltage in phase A (c) Voltage at Load (d) 
For the operation of the SRG in closed loop a transient load test was realized. The load resistance was reduced from $25 \Omega$ to $11 \Omega$, according the simulation test. For this situation, the generated voltage of reference was set in $110 \mathrm{~V}$ and the speed in 1500rpm. The Fig. 16(a) shows the behavior of the generated voltage applied to the load during the transient load. Notice that the reference value $(110 \mathrm{~V})$ was properly held demonstrating that the control was able to keep the generated voltage around the reference value even during the load transient. For the same situation a Fig. 16(a) shows the current in one of the phase's machine. The Fig. 16(b) shows the voltage and current for one of the phases.

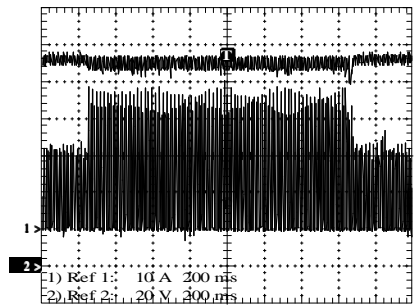

(a)

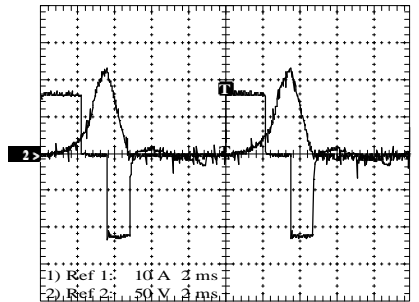

(b)
Fig. 16- Operation in closed-loop transient load. Load voltage and current in phase A (a) - Voltage and current in phase A (b)

Another test was realized now with the speed transient. The SRG controlled in a closed loop with reference of 110 $\mathrm{V}$ was accelerated from 800 to $2000 \mathrm{rpm}$. In Fig. 17 notice that the generated voltage remained with the value around to reference. See also that the oscillation amplitude present in the load voltage reduces with the increase in the speed, which is characteristic of this type of machine, by presenting large oscillations in the electromagnetic torque in low speed operation. There are works on the literature that aim to minimize these oscillations [9].

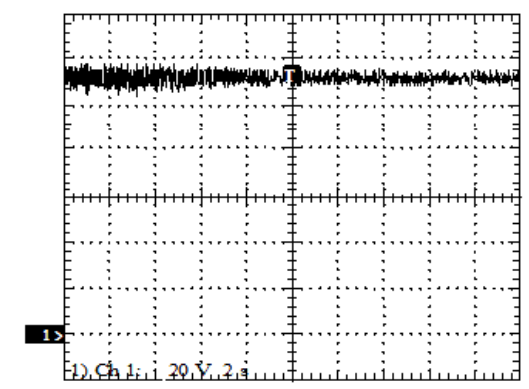

Fig. 17-SRG load voltage with variable speed

\section{Conclusion}

A control technique of the load voltage in a switched reluctance generator based on the variation of the magnetization angle using an intermediate freewheel step was proposed in this work. This technique varies only the closing angle of top switches of the HB converter, allowing that the electromagnetic conversion of energy continue to be exploited through the bottom switches that are open with fixed angle. The control strategy proposed was implemented in forms of simulation and experimentally. The results presented shows that this technique of control is satisfactorily the load voltage with the SRG operating in different situations of transient. Moreover was proven the importance of adding the intermediate freewheel step proposed for a better use of mechanic energy.

\section{Acknowledgement}

The authors are grateful to FAPEMIG for supporting the development of this work.

\section{References}

[1] J. M. Miller, A. V. Rajarathnam, and M. Ehsani, "Current status and future trends in more electric car power systems," Proc. IEEE Veh. Technol. Conf., Houston, TX, Maio 1999 pp. 23-29

[2] S. R. MacMinn and W. D. Jones, "A very high speed switched-reluctance starter-generator for aircraft engine applications" in Proc. IEEE Aerosp. And Electron. Conf., 1989, vol. 4, pp. 1758-1764.

[3] B. Fahimi, et. al., "A switched reluctance machinebased starter/alternator for more electric cars" Trans. Energ. Conver., vol. 19, nº 1, Março 2004.

[4] Cai. W, "Comparison and review of electric machines for integrated starter alternator applications," IEEE IAS, 2004.

[5] R. Cardenas, at. al. "Control of a switched reluctance generator for variable-speed wind energy applications "Trans. on Energy Convertion, Vol. 20, 2005.

[6] Y. Chang, C.M. Liaw, "On the design of power circuit and control scheme for switched reluctance generator" Transactions on Power Electronics, vol. 23, no. 1, 2008.

[7] D.A, Torrey. (2002), "Switched reluctance generators and their control", IEEE Transactions on Industrial Electronics, Volume 49, Issue 1, Feb. 2002, pp. 3-14.

[8] A. W. F. V. Silveira, D. A. Andrade, A. Fleury, L. C. Gomes, C. A. Bissochi Jr, H. de Paula "Generated Voltage Control In A Switched Reluctance Motor/Generator" Eletrônica de Potência, v. 15, n. 3, p. 203-212, jun./ago. 2010.

[9] Hao Chen, Senior Member, IEEE, and Jason J. Gu, Senior Member, IEEE. "Implementation of the ThreePhase Switched Reluctance Machine System for Motors and Generators" IEEE/ASME Transactions On Mechatronics, Vol. 15, No. 3, June 2010.

[10] A. V. S. Fleury, F. S. Silva; W. R. H. Araújo, D.A. Andrade, A. W. F. V. Silveira "Reduced switch count converter for switched reluctance generators" Eletrônica de Potência, Vol. 13, no. 3, Agosto 2008.

[11] Andrade, D. A., Krishnan, R. "Characterization of Switched Reluctance Machines Using Fourier Series Approach" in Proc. 36th IEEE Ind. Appl. Annu. Meeting, Sep. 2001, pp. 48-54.

[12] Hanmei, P., Lingzhi,Y. "Increasing Output Power of Switched Reluctance Generator With Three-level Power Converter" Power and Energy Engineering Conference (APPEEC), 2011 Asia-Pacific 